\title{
Das Europäische Verfahren für geringfügige Forderungen
}

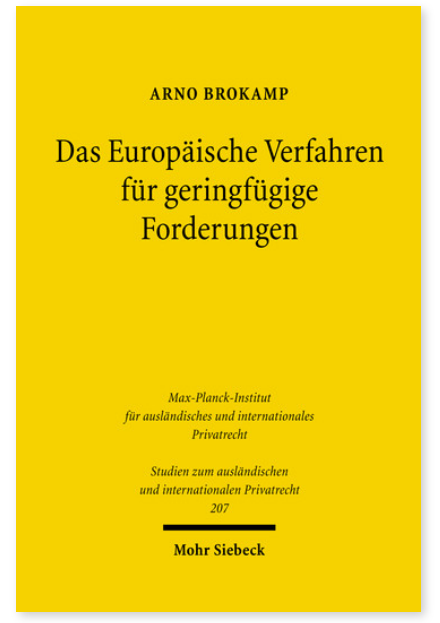

2008. XIX, 190 Seiten. StudIPR 207

ISBN 978-3-16-151392-3

DOI 10.1628/978-3-16-151392-3

eBook PDF 69,00€

ISBN 978-3-16-149810-7

fadengeheftete Broschur $69,00 €$
Mit dem Europäischen Verfahren für geringfügige Forderungen hat der europäische Gesetzgeber erstmals ein europaweit einheitliches kontradiktorisches Erkenntnisverfahren geschaffen. Das Regelungswerk markiert ein historisches Datum in der Entwicklung des Europäischen Zivilprozessrechts, weshalb es gleichermaßen für Rechtsanwender wie für die Wissenschaft von Interesse ist.

Arno Brokamp stellt die einzelnen Regelungen des Erkenntnisverfahrens vor und gibt der Praxis Hinweise, wie die zahlreichen Fragen und Unstimmigkeiten des mit Beginn des Jahres 2009 anwendbaren Verfahrens zu bewältigen sind. Dafür bedient er sich insbesondere der historisch-genetischen Methode. Da das Verfahren nur kursorisch geregelt wird, ist vielerorts auf das Zusammenspiel mit anderen Verordnungen auf dem Gebiet des Europäischen Zivilprozessrechts und mit dem subsidiär geltenden deutschen Prozessrecht einzugehen. Dessen Lösungen müssen aus einem Vergleich mit entsprechenden Konstellationen im nationalen Zivilverfahren gewonnen werden. Hat sich die betreffende Frage im deutschen Prozessrecht bisher überhaupt nicht gestellt, muss eine Antwort erst entwickelt werden. Dabei ist den Wertungen der höherrangigen Verordnung Rechnung zu tragen.

Der Autor richtet sein weiteres Augenmerk auf das Spannungsverhältnis zwischen Vereinfachungsbestreben und der Wahrung von Justizgrundrechten. Dies betrifft vor allem den Anspruch auf eine mündliche Verhandlung, die von der Verordnung in das Ermessen des Richters gestellt wird.

Das Buch wurde mit dem Hochschulpreis der Rechtsanwaltskammer München ausgezeichnet.

Arno Brokamp Geboren 1978; Studium der Rechtswissenschaft, Südostasienwissenschaft und Wirtschaftswissenschaften in Passau; 2008 Promotion; seit 2007 Rechtsreferendar in Hamburg.

\section{Jetzt bestellen:}

https://mohrsiebeck.com/buch/das-europaeische-verfahren-fuer-geringfuegige-forderungen-9783161513923?no_cache=1 order@mohrsiebeck.com

Telefon: +49 (0)7071-923-17

Telefax: +49 (0)7071-51104 